\title{
Protection against Advanced Glycation End Products and the Mode of Action of Lemon Balm on Hemoglobin Fructose-Mediated Glycation
}

Mehran Miroliaei ${ }^{1,2 *}$, Peymaneh Shafaei', Akram Aminjafari', Danial Barati², Riley Meekins ${ }^{2}$, Safaa Kader ${ }^{2}$, Kostelnik J. Colton² and Esmaiel Jabbari $^{*}$

${ }^{1}$ Biochemistry and Molecular Biology Division, Department of Biology, Faculty of Sciences, University of Isfahan, Isfahan, Iran

${ }^{2}$ Chemical and Biomedical Engineering, Swearingen Engineering Center, Rm 2C11, University of South Carolina, Columbia SC 29208, USA

\begin{abstract}
The present communication reports on changes in the secondary and tertiary structures of Hemoglobin $(\mathrm{Hb})$ upon fructation. The presence of Lemon balm (LB) provided significant protection toward the formation of early (HbA1c) and advanced glycation end products (Hb-AGEs), as evident from circular dichroism (CD) and fluorescence studies. The degree of AGE modification and its inhibition were characterized with intrinsic fluorescence, the fibrillar state, and the exposure of hydrophobic clusters. An increased signal of intrinsic fluorescence was observed upon glycation, particularly in the later stage of fructation. Glycation mediated fibril formation and its inhibition were assessed by Thioflavin T (ThT) assay. These sequence of events were parallel with an increase in $\beta$-sheet content from $\sim 2$ to $13 \%$ for $\mathrm{Hb}-\mathrm{AGE}$, as evidenced by Congo red binding and $\mathrm{CD}$. Furthermore, the late stage of glycation was also marked by an increase loss of heme moiety, confirming the relatively high affinity of ANS toward glycated-globin which was mitigated by applying the balm extract. However, the activity of balm can be attributed to inhibition of oxidative stress and free radicals derived from $\mathrm{Hb}-\mathrm{AGE}$, or chelation of metal ions producing in Fenton reaction. Overall, the presence of LB provided significant protection against AGE-induced deleterious processes, can qualify the herb as an effective AGE-inhibitor with potential prevention toward diabetic complications arising from $\mathrm{Hb}$ glycation.
\end{abstract}

Keywords: Human hemoglobin; Protein glycation; Hb-AGE; Folk medicine; Fructation

\section{Introduction}

Formation of advanced glycation end products (AGEs) is a hallmark of long-standing hyperglycemia. Glycation (sometimes called nonenzymatic glycosylation) is the result of the covalent bonding of a sugar molecule, such as glucose or fructose, to a protein or lipid molecule, without the controlling action of an enzyme. Glycation may occur either inside the body (endogenous glycation) or outside the body (exogenous glycation). It is a haphazard process that impairs the functioning of biomolecules. In vivo, advanced glycation of proteins has major contribution to the biomolecular damage in chronic diseases, such as diabetes, neural and microvascular abnormalities, and Alzheimer's disease [1]. It seems that intracellular AGE can be derived in multiple pathways, the Maillard reaction of asparagine and lysine representing the principal one. Via direct and receptor-dependent manner, AGEs exert their pathogenetic role in the development of multiple diabetic complications, such as atherosclerosis, retinopathy, neuropathy and nephropathy $[2,3]$. Therefore, the occurrence of extensive protein glycation in targeted tissues and/or organ sites causes interruption of normal protein structure and biological function, prompting the search for suitable medicines that could control the process. However, long-standing hyperglycemia has revealed to promote spontaneous glycation of $\mathrm{Hb}$ and causes severe progression of $\mathrm{Hb}-\mathrm{AGE}$ formation [4]. Hb-AGE has substantial contribution to intracellular generation of reactive species of oxygen (ROS), nitrogen (RNS), and free radicals in $\mathrm{RBC}[5,6]$. In this respect, several alterations are assumed to influence the biological function with the formation of glycated-Hb including: substantial remodeling of native conformation, intrinsic secondary structural changes, heme dissociation, decreased amino and free thiol group content, etc. The heterogeneous glycation products derived from $\mathrm{Hb}$ are often used as glycation models for in vivo and in vitro studies to quality the involvement of AGEs in cellular pathophysiology. Thus, based on these crucial aspects, many efforts have been devoted to finding effective anti-glycative agents.
A key aim of therapy in diabetic patients is to reduce hyperglycaemia by modification of the diet. However, dietary compliance is often difficult, and an alternative is to use pharmacological compounds that can reduce AGEs. Numerous compounds have been investigated for anti-glycation activity but their use in humans is still debatable. Natural medicines abundant in polyphenols might have therapeutic modalities for intervention in multifactor and complex reactions of AGE formation in different oxidative-based diseases. Melissa officinalis L., commonly known as lemon balm (LB), is a folk medicine characterized by unique high polyphenolic content $[7,8]$ with medicinal properties such as, anti-inflammatory, antiviral, memory enhancer, cardiac tonic, anti-depressant, sleeping aid, and antioxidant activity [9-14]. Phenolic acids, the main active ingredients present in the extract of LB are reported for anti-oxidative [15], anti-proliferative [16], antiinflammatory [17], anti-angiogenic [18] and anti-cancer properties $[19,20]$. The traditional use of LB extract has been proven in lowering blood glucose levels [21,22]. Accordingly, controlled studies were conducted to determine if balm could interfere with the chemical processes and mechanisms that ultimately lead to Hb-AGE. To identify the effect of LB in limiting the progression of AGE-induced toxicity, $\mathrm{Hb}$ was exposed to fructose and the pattern of structural alterations, heme degradation, fibril formation, lysine content, and the related oxidation fashion were monitored in the presence of lemon balm.

Corresponding authors: Mehran Miroliaei, PhD, Biochemistry, Cell and Molecular Biology, Department of Biology, Faculty of Sciences, University of Isfahan, Isfahan, Iran, Tel: +98(311)793-2475; Fax: +98(311)793-2456; E-mail: m.miroliaei@sci.ui.ac.ir

Esmaeil Jabbari, Ph.D, Department of Biology, Faculty of Sciences, University of Isfahan, Isfahan, Iran, Tel: (803) 777-8022. Fax: (803) 777-0973. E-mail: jabbari@mailbox.sc.edu

Received October 16, 2017; Accepted October 23, 2017; Published October 29, 2017

Citation: Miroliaei M, Shafaei P, Aminjafari A, Barati D, Meekins R, et al. (2017) Protection against Advanced Glycation End Products and the Mode of Action of Lemon Balm on Hemoglobin Fructose-Mediated Glycation. Med Chem 7: 314-320. doi: 10.4172/2161-0444.1000474

Copyright: (c) 2017 Miroliaei M, et al. This is an open-access article distributed under the terms of the Creative Commons Attribution License, which permits unrestricted use, distribution, and reproduction in any medium, provided the original author and source are credited. 


\section{Materials and Methods}

\section{Materials}

All chemicals used in this study were obtained from Sigma-Aldrich or Merck. All other chemicals were of reagent grade.

\section{Plant extraction}

The extract of LB was prepared as previously described [23]. The LB leaves were air-dried and made into powder. $1 \mathrm{~g}$ of the powder was shaken gently with $5 \mathrm{~mL}$ dichloromethane. After filtration, samples were extracted with $45 \%$ aqueous ethanol, filtered, freeze-dried and stored at $4^{\circ} \mathrm{C}$. The dried extract was weighed, diluted appropriately with water, and immediately used in assays. The concentration of the extract was $2 \mathrm{mg} / \mathrm{mL}$ in the test solutions.

\section{High Performance Liquid Chromatography (HPLC)}

The contents of RA in extracts from LB were determined by HPLC performed on a Hitachi liquid chromatograph (Hitachi, Ltd., Tokyo, Japan), which consisted of a model L-2130 pump and a model L-2455 photo diode array detector set at $280 \mathrm{~nm}$. A reversed phase LiChrosphere RP-18 column was used for HPLC analysis. Elution was carried out at room temperature and utilized 2\% (v/v) acetic acid in water as solvent $A$ and $0.5 \%$ acetic acid in water and acetonitrile (50:50, $\mathrm{v} / \mathrm{v}$ ) as solvent $\mathrm{B}$. Phenolic compounds were identified by comparison of their retention times (Rt) and UV-Vis spectra [24].

\section{Glycation analysis}

Preparation of glycated hemoglobin: Glycated $\mathrm{Hb}$ was prepared and characterized as described previously $[25,26]$. $\mathrm{Hb}(0.75 \mathrm{mM})$ was incubated at $37^{\circ} \mathrm{C}$ in a solution of D-fructose $(50 \mathrm{mM})$ in 0.1 $\mathrm{M}$ phosphate buffer saline (PBS, $\mathrm{pH} 7.4$ ) in the presence or absence of Melissa extract $(0.2 \mathrm{mg} / \mathrm{mL}) .0 .02 \%(\mathrm{w} / \mathrm{v}) \mathrm{NaN}_{3}$ was added to the solution to prevent bacterial contamination and filtered through a low protein binding filter (Millex-GV $0.22 \mu \mathrm{m}$ filter unit, Millipore). Aliquots were taken from the $\mathrm{Hb}$-fructose solution after each period of incubation and extensively dialyzed against autoclaved PBS at $4^{\circ} \mathrm{C}$ to remove unreacted fructose. Pure $\mathrm{Hb}$ was incubated under the same conditions as the control sample.

Determination of glycation: The amount of glycation in $\mathrm{Hb}$ was determined using the brown staining method [27]. Optical density of 1 $\mathrm{mg} / \mathrm{mL}$ protein of each sample ( $\mathrm{pH} 7.4$ ) was recorded by measuring the absorbance at $340 \mathrm{~nm}$ with a UV60A spectrophotometer (Shimadzu).

Determination of free amino groups using fluorescamine: $1 \mu \mathrm{l}$ protein solution $(10 \mathrm{mg} / \mathrm{ml}), 100 \mu \mathrm{Na}_{2} \mathrm{HPO}_{4}(100 \mathrm{mM}), 45 \mu \mathrm{l}$ distilled water, and $50 \mu \mathrm{l}$ fluorescamine reagent solution $(1 \mathrm{mM}$ fluorescamine in acetonitrile) were mixed and incubated for 10-15 min in dark in a 96-well plate. The fluorescence intensity of fluorescamine was measured at excitation and emission wavelengths, 390/490 $\mathrm{nm}$ in a Carry spectrofluorometer. The percentage of free amino groups was calculated according the relation:

$$
\text { Percentage of free amino group }=\frac{\text { Fluorescene emission of } \mathrm{HBin} \text { desired condition }}{\text { Fluorescence emission of } \mathrm{Hb}} \times 100 \%
$$

AGEs analysis: The amount of glycation was evaluated by an AGE-related auto-fluorescence assay. Fluorescence was measured for relevant samples $(0.15 \mathrm{mg} / \mathrm{mL})$ recorded at wavelengths of $370 / 440$ $\mathrm{nm}$ [28]. Correction for spectra was done with appropriate protein and buffer blanks.

ThT Binding assay: ThT fluorescent assay was performed as an indicator of amyloid fibrillation [29]. $10 \mu \mathrm{L}$ of $\mathrm{Hb}$ samples were added to $590 \mu \mathrm{L}$ of $25 \mu \mathrm{M}$ ThT solution $(2.5 \mathrm{mM}$ ThT stock solution in 25 $\mathrm{mM}$ sodium phosphate buffer, $\mathrm{pH} 6$, passed through a $0.45 \mu \mathrm{m}$ filter paper). Fluorescent emission spectra were recorded at $490 \mathrm{~nm}$ with an excitation wavelength of $445 \mathrm{~nm}$. The excitation and emission slit widths were set as 5 and $10 \mathrm{~nm}$, respectively [30].

Heme release measurements: Heme loss associated with fructation was monitored by measuring the absorbance spectrum of fructated $\mathrm{Hb}$. Aliquots were pulled on a daily basis for 6 days. The average of three independent measurements of the absorbance at the Soret peak (415 $\mathrm{nm}$ ) was recorded as a function of incubation time. Absorption spectra were recorded for $\mathrm{Hb}$-fr samples after 30 days incubation in varying concentrations of sugars to follow the status of heme moiety.

Congo red assay: Congo red (CR) binding assay was performed as described previously [23]. Binding of CR was detected by measuring the absorbance at $530 \mathrm{~nm} .800 \mu \mathrm{L}$ of protein solution $(100 \mu \mathrm{M})$ was incubated with $200 \mu \mathrm{L}$ of CR solution ( $100 \mu \mathrm{M}$ Congo red in PBS containing ethanol $10 \%(\mathrm{v} / \mathrm{v})$ ). Absorbance at $530 \mathrm{~nm}$ was recorded for CR-incubated samples, as well as for CR and protein for background correction.

Circular dichroism spectropolarimetry: Far-UV CD spectra of the samples were recorded at ambient condition on a J-715 spectropolarimeter (Jasco) using solutions with a protein concentration of about 0.15 to $0.2 \mathrm{mg} / \mathrm{mL}$. Each spectrum after correction for the respective blanks is the average of four scans. Results are expressed as molar ellipticity, $[\Theta]\left(\mathrm{deg} \mathrm{cm}^{2} \mathrm{dmol}^{-1}\right)$ based on a mean amino acid residue weight $(\mathrm{MRW})$. The molar ellipticity was determined as $[\Theta]$ $=(\Theta \times 100 \mathrm{MRW}) /(\mathrm{cl})$, where $\mathrm{c}$ is the protein concentration in $\mathrm{mg} / \mathrm{mL}$, 1 is the light path length in centimeters, and $\Theta$ is the measured ellipticity in degrees at a wavelength $\lambda$. The relative percentages of the secondary structural elements were estimated using SELCON3 software.

\section{Cell culture and MTS assay}

Three mammalian cell lines, human embryonic kidney cells (HEK293), normal human fibroblasts, and Chinese hamster ovary cells (CHO), were maintained in DMEM medium supplemented with $10 \%$ fetal bovine serum (FBS), $1 \%$ antibiotic solution at $37^{\circ} \mathrm{C}$, and $5 \% \mathrm{CO}_{2}$ atmosphere. They were in the logarithmic phase of growth at the time of MTS (3-(4,5-dimethylthiazol-2-yl)-5-(3-carboxymethoxyphenyl)2-(4-sulfophenyl)-2H-tetrazolium) assay. Cells were harvested for the viability test and seeded into a 96 -well tissue culture plate at a density of $1 \times 10^{4}$ cells per well. The cells were allowed to adhere to the wells for $24 \mathrm{~h}$ at $37^{\circ} \mathrm{C}$ in a humidified atmosphere optimized with $5 \% \mathrm{CO}_{2}$. After replacement of the medium, $\mathrm{Hb}, \mathrm{Hb}-\mathrm{fr}$, and $\mathrm{Hb}-\mathrm{fr}-\mathrm{LB}$ were added to the cells seeded on wells. Cells were grown for an additional $24 \mathrm{~h}$ before being subjected to viability test. MTS was added to wells the next day and incubated for $4 \mathrm{~h}$. All experiments were performed at least three times. Phosphate-buffered saline (PBS) was used as a negative. The toxic endpoints were determined at $492 \mathrm{~nm}$ after $4 \mathrm{~h}$ exposure. Viability of cells defined as the inhibitory concentration ( $\mathrm{IC}_{50}$ ):

The estimated $\mathrm{IC}_{50}$ values of samples (concentration causing death of $50 \%$ of cells)

$$
\% \text { viability }=\left(\frac{\text { Testabs }}{\text { Control abs }}\right) \times 100 \%
$$

\section{Statistical analysis}

All experiments were performed in triplicates. Mean, standard error, standard deviation, one-way ANOVA, and paired t-test were calculated from replicates within the experiments and analyses were done using SPSS Version 22. Statistical significance was accepted at a 
level of $\mathrm{P}<0.05$.

\section{Results and Discussion}

To address the question if the early product of $\mathrm{Hb}$-fructose $\left(\mathrm{HbA}_{1} \mathrm{c}\right)$ mitigates in the presence of extract, we tested its effect on browning reactions (usually Maillard type reactions). There was a significant difference between $\mathrm{OD}_{340}$ of fructated- $\mathrm{Hb}$ and balm treated samples (Figure 1). The lower absorbance at relevant wavelength for the treated samples represents the attenuation of the Maillard reaction during the initial stage of fructation. From chemical viewpoint, AGEs are formed by a three-step mechanism in which intense brown pigments appear at the early stage [27]. Since the generation of superoxide radicals is favored by transition metals at the glycoxidation phase of the Maillard reaction [31-33], established superoxide radical scavenging with metal chelating activity of balm extract are suggested in contributing to the observed inhibitory $[12,23]$. Similar metal chelating activity has been reported for guava leaf extract [34]. Figure 2 shows the extent of reacted amino groups of glycated samples using fluorescamine assay [35]. The amount of free lysines in HB was decreased significantly (70\%) in the presence of fructose, while LB appreciably protected them from glycation (Figure 2).

It has been shown that fructose modifies the secondary structure of $\mathrm{Hb}$ by exposing the solvent-accessible surface area of the sites prone to glycation [36]. The CR method is a well-known assay for cross- $\beta$ structure in the glycated protein and displays specific absorption at 530 $\mathrm{nm}$ after binding [37]. An amyloid-specific increase in intensity at 530 $\mathrm{nm}$ was observed when the absorbance was recorded for solutions of CR-Hb samples (Figure 3). Fructose-induced alteration in the canonical secondary structure of native $\mathrm{Hb}$ was reduced with the addition of $\mathrm{LB}$ extract. The late stage of $\mathrm{Hb}$ glycation has been marked by an increase of $\beta$-structure at the expense of $\alpha$-helical structure [38]. The reduction in $\mathrm{OD}_{530}$ for LB extract treated samples (Figure 3 ) concluded that LB extract is able to prevent the conversion of native $\alpha$-helical structure to $\beta$ - conformer.

A CD spectropolarimetry was employed in the far-UV region (200 to $250 \mathrm{~nm}$ ) to independently confirm the results obtained with CR. It was observed that the extent of alterations was much higher for the samples incubated with fructose than with the control. The addition of LB significantly reduced those structural alterations and shielded the secondary structure of $\mathrm{Hb}$ from harmful effects of fructose (Figure 4). The $\alpha$-helix content of the $\mathrm{HbA}_{0}$ and $\mathrm{Fr}-\mathrm{Hb}$ samples estimated by the adsorption at $222 \mathrm{~nm}$ was approximately $62 \%$ and $41 \%$, respectively, comparable with the samples treated with LB extract (Table 1). These observations were consistent with the proposed anti-amyloid properties of LB extract [23] in retarding the changes in $\alpha$-conformers by shielding the glycation sites, lowering the extent of solvent accessible surface area, and forming a barrier for cross $\beta$-structure formation. It has been reported that glycation induces refolding of the globular proteins into amyloid fibrils comprising of cross- $\beta$ structure [39]. The behavior of LB extract in this respect resembles that of molecular chaperones that block the hydrophobic surfaces of proteins.

At the early stage of glycation, fructose controls the $\mathrm{Hb}$ structure such that the heme moiety is no longer engaged in $\mathrm{Hb}$ structure and released from the protein [26]. This heme liberation from $\mathrm{Hb}$ is responsible for the majority of the pathology associated with diabetic complications [38]. The extent of fructose-induced damage was significantly higher for native $\mathrm{Hb}$ samples than those treated with LB extract (Figure 5). Fructation affects the structural integrity of the assembly of $\alpha$ - and $\beta$-chains in $\mathrm{Hb}$ as heme helps to maintain the overall integrity. Glycation gives rise to major conformational changes in the heme pocket. The process attenuates the forces holding the heme moiety to $\mathrm{Hb}$, which leads to its release from the hydrophobic pocket. This is consistent with the hypothesis that ROS production follows heme liberation upon $\mathrm{Hb}$ fructation [25]. Glycation of ceruloplasmin by methylglyoxal also leads to liberation of copper ions [39]. Release of trace metals, such as iron and copper, from metalloproteins is attributed to ROS production, which leads to changes in protein structure $[25,40]$. It was proposed that the inhibitory effects of LB extract result from its recognized ROS scavenging properties [12] because the addition of LB extract impeded ROS production at the early stage of autoxidative fructation (Figure 1). The reverse effect of LB extract on heme degradation and conformational alteration of $\mathrm{Hb}$ originates from its controlling action on the $\beta$-amyloid structure formation. A feature of glycated proteins is the propensity to condense into amyloid fibrils, which are characterized by a specific quaternary structure element known as cross- $\beta$ structure [41]. In contrast to the holo structure, removal of the prosthetic group from many proteins results in apo forms which commonly leads to the formation of the amyloid structure [29]. A synergistic mechanism is proposed for LB action in that antioxidant and ROS scavenging activities are engaged

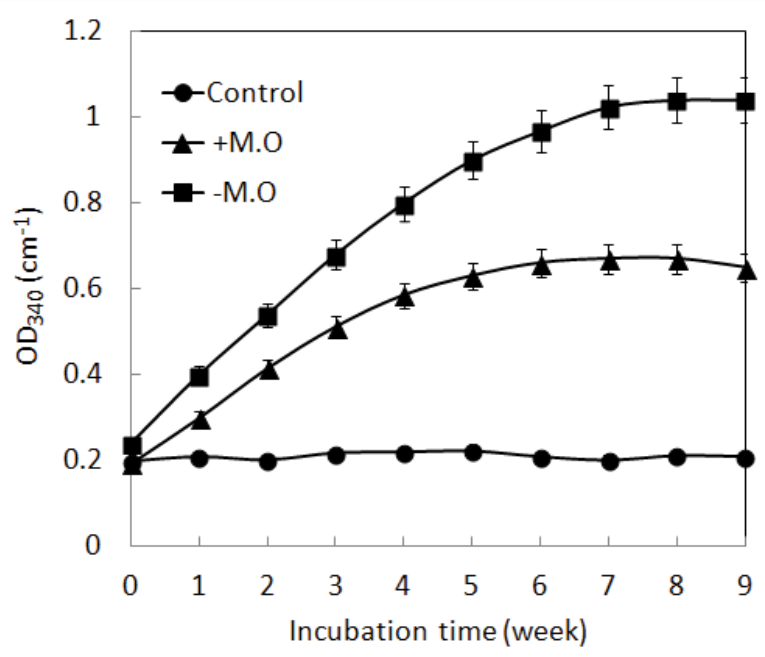

Figure 1: Brownish color absorbance of $\mathrm{Hb}$ at $340 \mathrm{~nm}$. Samples were incubated with fructose for 9 weeks in the presence and absence of LB extract. Control samples for $\mathrm{Hb}$ were incubated with and without LB extract in the absence of fructose.

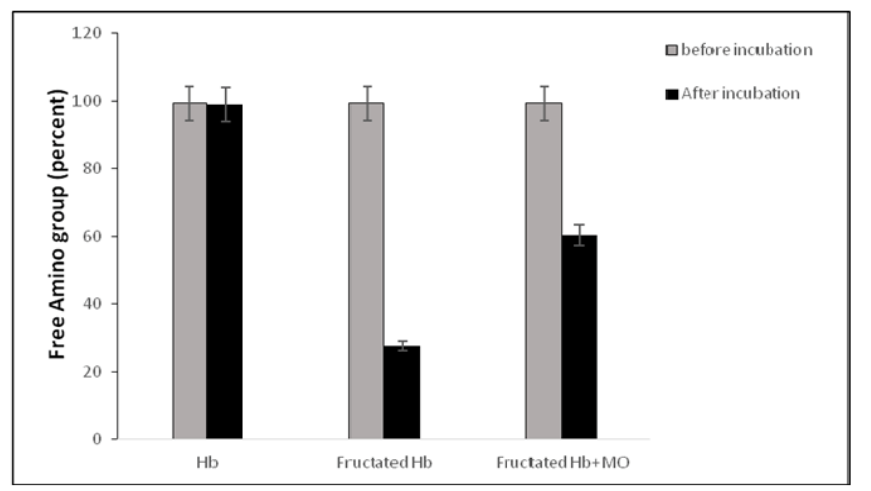

Percentage of amino group

Figure 2: Percentage of free amino groups after incubation of hemoglobin samples for 5 weeks in $50 \mathrm{mM}$ phosphate buffer, $\mathrm{pH} 7.4$ at $37^{\circ} \mathrm{C}$ with 1) no additives (control), 2) $50 \mathrm{mM}$ fructose, and 3) $50 \mathrm{mM}$ fructose and $10 \mu \mathrm{g} / \mathrm{ml}$ MO extract. 


\begin{tabular}{|c|c|c|c|}
\hline Sample & Control & -M.O & +M.O \\
\hline $\boldsymbol{\alpha}$-Helix & $62.52 \pm 1.1$ & $41.21 \pm 1.31$ & $59.16 \pm 3.1$ \\
\hline $\boldsymbol{\beta}$-Sheet & $2.11 \pm 0.8$ & $13.07 \pm 1.2$ & $7.1 \pm 1.5$ \\
\hline
\end{tabular}

Table 1: Effect of lemon balm extract on secondary structural content of $\mathrm{Hb}$. SELCON3 software was used for estimating the relative percentages of the secondary structural elements.

in carbonyl generation during $\mathrm{Hb}$-fructation. It can be concluded that fructose is capable of inducing amyloid cross- $\beta$ formation in the $\mathrm{Hb}$ structure based on CD spectral and CR staining results.

A binding assay specific to the amyloid marker ThT was used to further determine if such structural changes occur in the fructated $\mathrm{Hb}$. ThT fluorescent emission was enhanced in Hb-AGE and significantly reduced in the LB-treated samples (Figure 6). It can be concluded based on the ThT fluorescent and CR staining data that high levels of fructose promote fibrillation in $\mathrm{Hb}$ structure and high levels of LB extract diminish fibrillation in $\mathrm{Hb}$ structure. The results are similar to the observed effect of acetylsalicylic acid on $\mathrm{Hb}$ structure, in which the agent suppresses $\beta$-sheet formation as a precursor to amyloid formation [42]. LB suppresses the ability of fructose to trigger the switch in $\mathrm{Hb}$ from the native globular fold into the amyloid cross- $\beta$ structure upon covalent binding.

The most common way of measuring glycation-induced alterations in proteins is a tryptophan fluorescent assay. Auto-fluorescent phenomena associated with the formation of a structurally distinct fluorophore $\left(\lambda_{\mathrm{ex}} / \lambda_{\mathrm{em}}=370 / 440 \mathrm{~nm}\right)$ is the hallmark of Hb-AGE production at the late stage of $\mathrm{Hb}$ glycation [43]. The auto-fluorescent spectra of the samples were recorded at an emission wavelength of 440 $\mathrm{nm}$ with and without the LB extract (Figure 7). Fructose increased the signals from AGE adducts mostly because of the appearance of species that correspond to high levels of protein modification. A conformational switchover in the protein molecules during the process of fructation gave rise to fluorescent $\mathrm{Hb}-\mathrm{AGE}$ adducts, whereas $\mathrm{HbAlc}$ failed to exhibit such fluorescent signals. Variations in the glycated adduct cannot be ruled out because glycation leads to the formation of both HbAlc and Hb-AGE with different auto-fluorescent signals. The emission spectra at $450 \mathrm{~nm}$ continued to increase monotonically with a slight blue shift. This is further evidence for Hb-AGE formation during the 9 weeks of incubation (Figure 8). A significant decrease in the fluorescent intensity of AGEs was observed with LB addition as shown in the inset of Figure 8. The fluorescent intensity was quenched by $54 \%$ with the addition of $1.0 \mathrm{mg} / \mathrm{mL}$ of LB extract compared to the control sample.

An ANS fluorescence assay was performed to further evaluate the effect of LB against AGE formation and to quantify the accessible surface-located hydrophobic regions of the protein [44]. Analyses of ANS emission peaks indicated that fructose dramatically increases fluorescent intensity and shifts the emission spectrum by $20 \mathrm{~nm}$ (hypsochromic effect) with incubation time (Figure 9). The fluorescent intensity did not change significantly when LB extract was added to the $\mathrm{Hb}$ sample, similar to the blank control. The addition of LB extract was able to prevent large conformational changes arising from enhanced surface hydrophobicity of glycated $\mathrm{Hb}$. Specific binding sites for ANS on the fructated $\mathrm{Hb}$ contributed to the observed hyperchromism of the fluorescent intensity [43]. It is likely that LB extract acts to limit access to ANS binding sites, prevents alterations to the protein tertiary structure, and reduces the formation of Hb-AGE adducts. Dissociation of heme moiety from $\mathrm{Hb}$ also exposes the hydrophobic residues, contributing to association between heme-globin and ANS. LB extract seems to protect the hydrophobic moieties from exposure to ANS upon

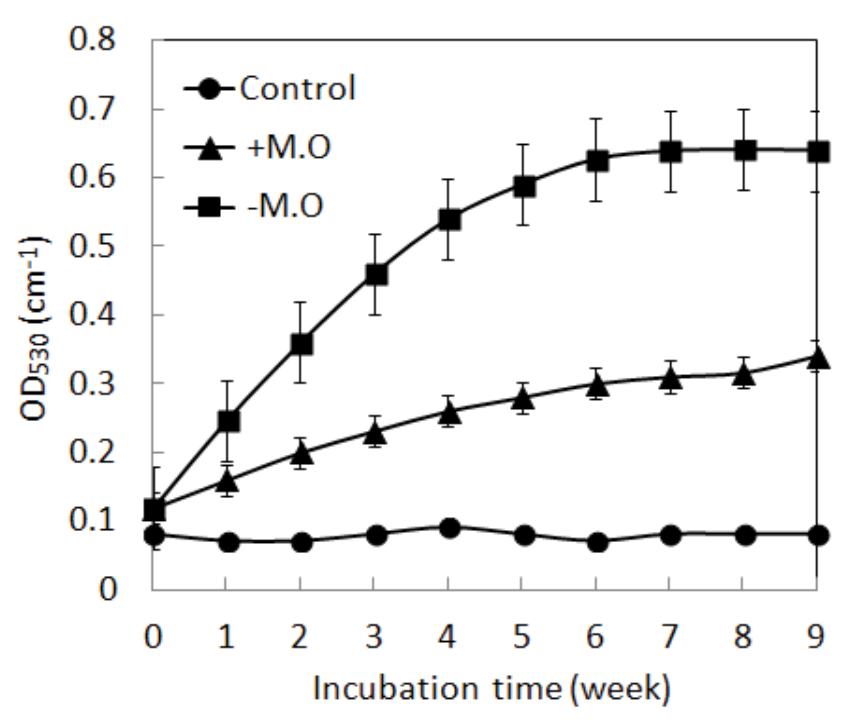

Figure 3: Time evolution of changes in the secondary structure of $\mathrm{Hb}$ as measured by Congo red assay at a wavelength of $530 \mathrm{~nm}$.

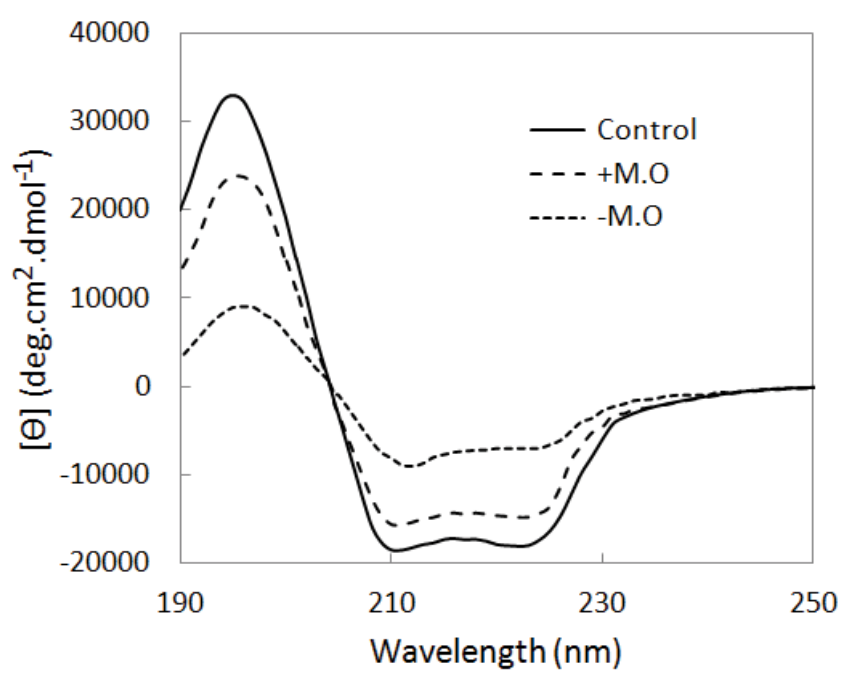

Figure 4: Far-UV CD spectra of $\mathrm{Hb}$. All samples were incubated for 9 weeks in PBS $(100 \mathrm{mM}, \mathrm{pH} 7.4)$ at $37^{\circ} \mathrm{C}$ for native $\mathrm{Hb}$ (control), in the presence (+MO) and absence of (-MO) of LB extract. The CD data was expressed as molar ellipticity $\left(\right.$ deg $\left.\mathrm{cm}^{2} \mathrm{dmol}^{-1}\right)$.

\section{$\mathrm{Hb}$ fructation.}

Auto-fluorescent signals are observed only after the Maillard reaction. This is consistent with the various adducts generated during the advancement of $\mathrm{Hb}$ glycation [45]. The results from the autofluorescent intensity at $308 / 345 \mathrm{~nm}\left(\lambda_{\mathrm{ex}} / \lambda_{\mathrm{em}}\right)$ confirmed that fructation increases the $\mathrm{Hb}$-AGE formation (Figure 10). These changes were reduced by the addition of LB extract. The presence of redox catalysts decreased AGE formation. This is conceivable because fructose can generate free-radicals and fructosamines can degrade by oxidation and form AGEs in the later stages (Figure 10). The results in Figure 10 provide evidence for accelerated consumption of ROS or reactive dicarbonyl intermediates and agree with the results in Figures 1 and 4 .

Advanced glycation end products (AGEs) arise from the reaction of sugars with side chains and the N-terminus of proteins. They 


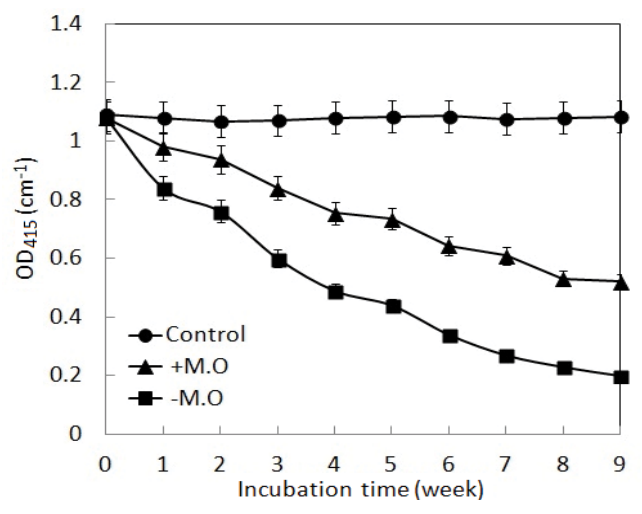

Figure 5: Kinetic changes in Soret peak measured at $415 \mathrm{~nm}$ wavelength during fructation. Absorbance spectra of $\mathrm{Hb}$ measured as a function of incubation with $0.05 \mathrm{M}$ fructose at $37^{\circ} \mathrm{C}$. HB was incubated with or without the LB extract in the absence of fructose in the control samples. Error bars are based on three independent measurements.

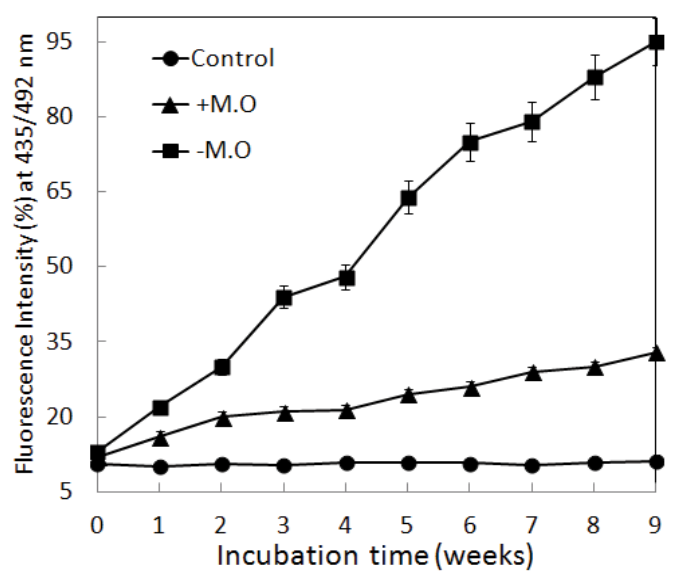

Figure 6: Amyloid fibrillation by $\mathrm{Hb}(0.75 \mathrm{mM})$ measured in PBS $(100 \mathrm{mM} \mathrm{pH}$ $7.4)$ at $37^{\circ} \mathrm{C}$. Kinetics of amyloid fibril formation was measured by increasing fluorescent intensity of ThT at $492 \mathrm{~nm}\left(\lambda_{\mathrm{em}}=435 \mathrm{~nm}\right)$. Changes in ThT fluorescent intensity of the samples incubated in the absence (-MO) and presence (+MO) of LB extract. $\mathrm{Hb}$ was incubated with or without the balm extract in the absence of fructose in the control samples.

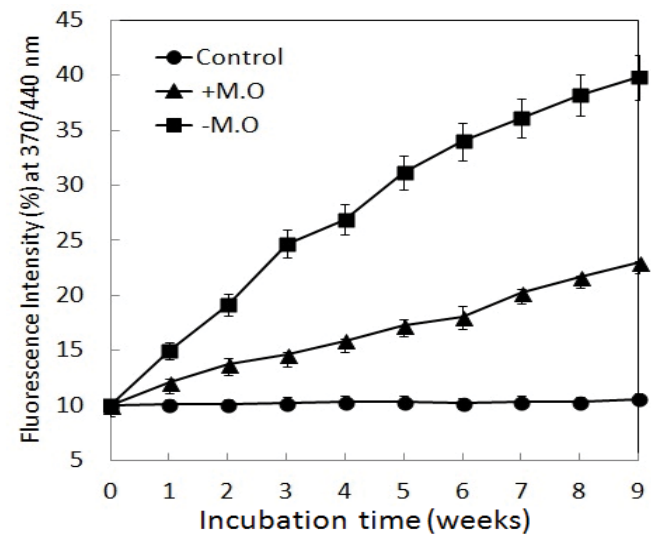

Figure 7: Fluorescent intensity of $\mathrm{Hb}-\mathrm{AGE}$ as a function of incubation of native$\mathrm{Hb}$ with $50 \mathrm{mM}$ fructose in the absence $(-\mathrm{MO})$ and presence $(+\mathrm{MO})$ of LB extract. Changes in excitation and emission $(\lambda / \lambda)$ wavelength of $370 / 440$ $\mathrm{nm}$ were recorded with and without the balm extract. $\mathrm{Hb}$ was incubated with or without the balm extract in the absence of fructose in the control samples.

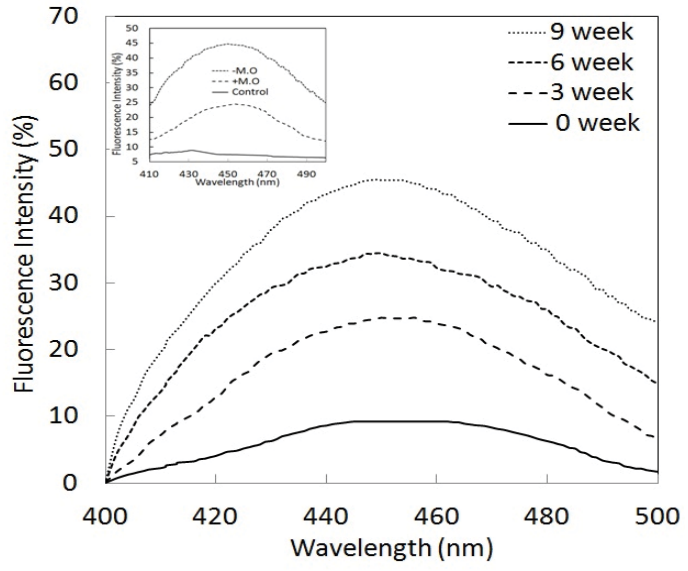

Figure 8: Fluorescent spectra of HSA-AGEs derived from fructose. Maximum fluorescent emissions were recorded in the wavelength range of $400-500 \mathrm{~nm}$ (after excitation at $370 \mathrm{~nm}$ ) for control and test samples in the absence and presence of LB extract for the 9 week incubation time. The inset spectrum shows a fluorescent intensity in the wavelength range of $410-500 \mathrm{~nm}$ in ascending order of time.

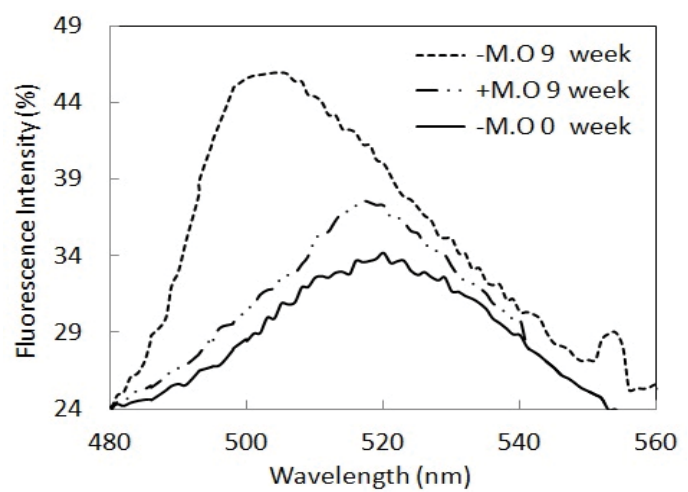

Figure 9: Fibrillation evolution of $\mathrm{Fr}-\mathrm{Hb}$ as assessed by ANS fluorescent intensity (through excitation and emission wavelength of $370 \mathrm{~nm}$ and 480 $522 \mathrm{~nm}$, respectively) over the 9 week incubation with and without LB extract. Spectrum of ANS alone is also included.

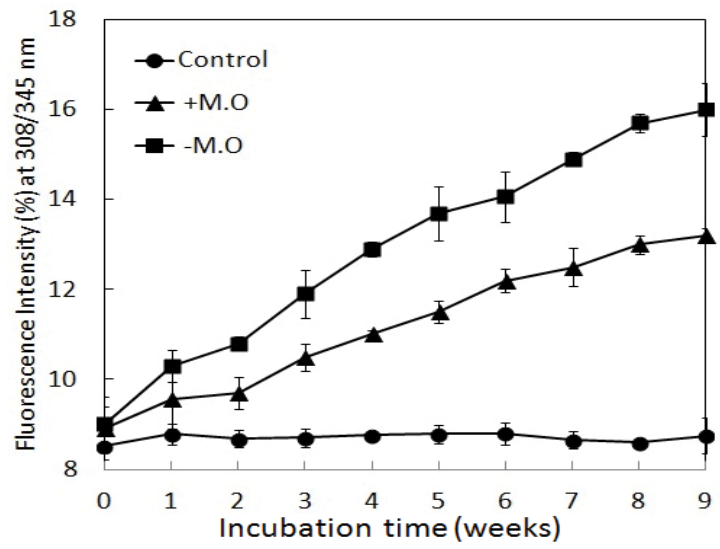

Figure 10: Effect of modification of lysine residues on the structure of $\mathrm{Hb}$ Evolution of intensity of fluorescent signal was recorded at an emission wavelength of $345 \mathrm{~nm}$ and of $308 \mathrm{~nm}$ after excitation. Fluorescent intensity did not change significantly in the absence of fructose (control) over the 9 week incubation. The spectral changes imposed by fructose (-MO) declined to a remarkable extent in the presence of LB extract $(+\mathrm{MO})$. 


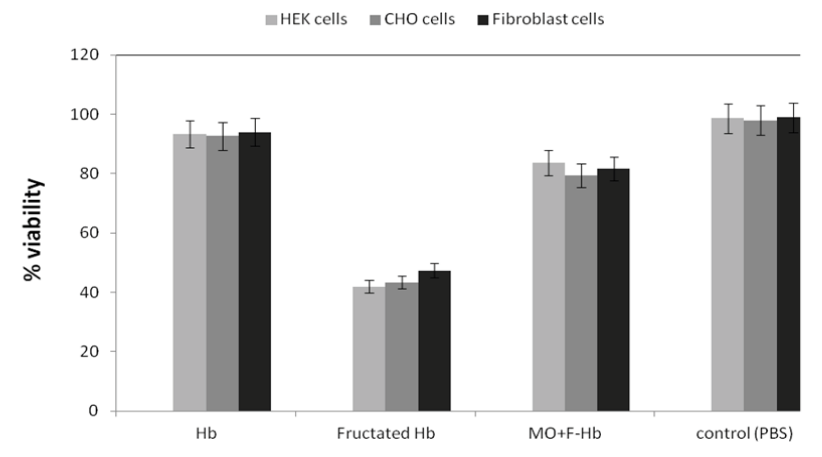

Figure 11: \% Viability=(Test absorbance/Control absorbance $) \times 100 \%$.

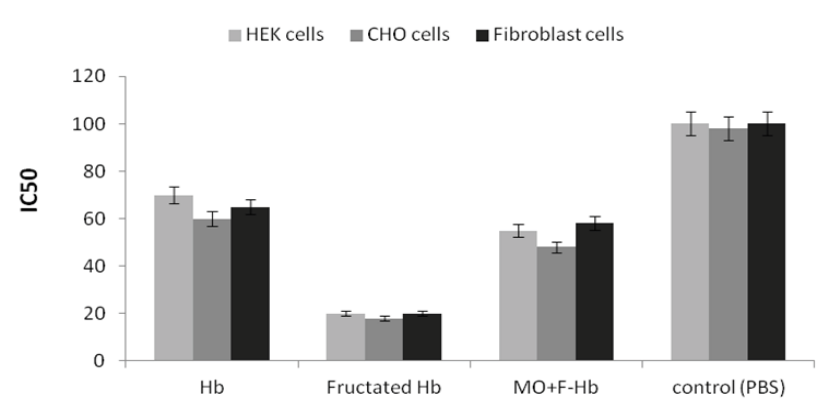

Figure 12: The inhibitory concentration $\left(\mathrm{IC}_{50}\right)$ : (Concentration $(\mu \mathrm{L})$ of sample needed to inhibit cell growth by $50 \%$ ) calculated by $\%=($ Blank-test/blank) $\times$ $100 \%$

are thought to be involved in the pathogenesis of several diseases by inducing oxidative stress, inflammation, and cell death and are presumably mediated through activation of the receptor of AGE (RAGE). The cell viability of the AGEs was tested to address the question of whether the cell damaging effect of AGE mitigates in presence of LB extract (Figure 11). MTS (3-(4,5-dimethylthiazol-2-yl)5-(3-carboxymethoxyphenyl)-2-(4-sulfophenyl)-2H-tetrazolium), in the presence of phenazine methosulfate (PMS), produces a formazan product that has an absorbance maximum between $490 \mathrm{~nm}$ and $500 \mathrm{~nm}$ in phosphate-buffered saline. glycated $\mathrm{Hb}$ significantly $(\mathrm{P}>0.05)$ inhibit mitochondrial respiration as measured by the MTS assay (Figure 11).

IC50 of $\mathrm{Hb}$ and of glycated $\mathrm{Hb}$ in the presence and absence of $\mathrm{LB}$ extract shows that glycated $\mathrm{Hb}$ in less concentration can decrease cell viability $(\mathrm{P}<0.05)$ (Figure 12$)$. This mitigates by applying LB extract $[46,47]$.

\section{Conclusion}

Results demonstrate that the multi-target mode of LB action in $\mathrm{Hb}$ fructation has potential therapeutic activity for the prevention of AGEinduced complications. It can be concluded that LB antioxidant activity directs its anti-glycation properties. This suggests the potential of LB to mitigate multiple complications stemming from oxidative stress and protein glycation in conformational disorders such as diabetes and ageing.

\section{References}

1. Gugliucci $A(2000)$ Glycation as the glucose link to diabetic complications. J Am Osteopath Assoc 100: 621-634.

2. Beisswenger P, Howell S, Russell G, et al. (2014) Detection of diabetic nephropathy from advanced glycation endproducts (AGEs) differs in plasma and urine, and is dependent on the method of preparation. Amino Acids 46:

\section{1-319.}

3. Panaskar SN, Joglekar MM, Taklikar SS, Haldavnekar VS, Arvindekar AU (2013) Aegle marmelos Correa leaf extract prevents secondary complications in streptozotocin-induced diabetic rats and demonstration of limonene as a potent antiglycating agent. Journal of Pharmacy and Pharmacology 65: 884894.

4. Khalifah RG, Baynes JW, Hudson BG (1999) Amadorins: novel post-Amadori inhibitors of advanced glycation reactions. Biochem Biophys Res Commun pp. 251-257.

5. Vinson JA, Howard TB (1996) Inhibition of protein glycation and advanced glycation end products by ascorbic acid and other vitamins and nutrients. Nutr. Biochem 7: 659-663.

6. Sevanian A, Ursini G (2000) Lipid peroxidation in membranes and low-density lipoproteins: similarities and differences. Free Radic Biol Med 29: 306- 311.

7. Allahverdiyev A (2004) Antiviral activity of the volatile oils of Melissa officinalis L. against Herpes simplexvirus type-2. Phytomedicine 11: 657-661.

8. Moradkhani M, Sargsyan S, Bibak H, Naseri B, Sadat-Hosseini M, et al. (2010) Melissa officinalis L., a valuable medicine plant: A review. Journal of Medicinal Plants Research Vol. 4: pp. 2753-2759.

9. Cogan, T (1636) The Haven of Health. Printed by Anne Griffin, London, p: 39.

10. Osbaldeston TA (2000) Dioscorides De Materia Medica. IBIDIS Press, Johannesburg, South Africa.

11. Evelyn J (1699) Acetaria: A Discourse Of Sallets. Available from: http://www bookrags.com/ ebooks/15517/1.html\#gsc.tab $1 / 40$

12. Dastmalchi K, Dorman HTD, Oinonen PP, Darwis Y, Laakso I, et al. (2008) Chemical composition and in vitro antioxidative activity of a lemon balm (Melissa officinalis L.) extract. Lwt-Food Science and Technology. 41: 391-400.

13. Jorjani J, Jorjani SE, Sirjani AA (2008) Zakhireh Kharazmshahi (A photo print of the manuscript dated 1206 A.D). The Iranian Culture Foundation, Tehran, p. 462.

14. Sina HI (1987) A Al-Qanun fi'l-Tibb (Canon of Medicine). IHMMR Printing Press, New Delhi.

15. Caniova A, Brandsteterova E (2001) HPLC analysis of phenolic acids in Melissa officinalis. J Liq Chrom Rel Technol 24: 2647-2659.

16. Makino T, Ono T, Musa E, Yoshida H, Honda G, et al. (2000) Inhibitory effects of rosmarinic acid on the proliferation of cultured murine mesangial cells. Nephrol Dial Transplant 15: 1140-1145.

17. Osakabe N, Yasuda A Natsume M, Yoshikawa T (2004) Rosmarinic acid inhibits epidermal inflammatory responses: anticarcinogenic effect of Perilla frutescens extract in the murine two-stage skin model. Carcinogenesis 25: 549557.

18. Huang SS, Zheng RL (2006) Rosmarinic acid inhibits angiogenesis and its mechanism of action in vitro. Cancer Lett 271-280.

19. Moon DO, Kim MO, Lee JD, Choi YH, Kim GY (2010) Rosmarinic acid cell death through suppression of TNF- $\alpha$ induced NFK-B activation and ROS generation in human leukemia U937 cells. Cancer Lett 288: 183-191.

20. Grzegorczyk-Karolak I, Gołab K, Gburek J (2016) Formation and Antioxidant Activity by Extracts and Polyphenols from Scutellaria alpina L. and S. altissima L. Molecules 21: 739.

21. Hasanein P, Riahi H (2015) Antinociceptive and antihyperglycemic effects of Melissa officinalis essential oil in an experimental model of diabetes. Med Princ Pract 24: 47-52.

22. Jang SM, Yee ST, Choi J (2009) Ursolic acid enhances the cellular immune system and pancreatic beta-cell function in streptozotocin-induced diabetic mice fed a high-fat diet. Int. Immunopharmacol 9: 113-119.

23. Miroliaei M, Khazaei S, Moshkelgosha S, Shirvani M (2011) Inhibitory effects of Lemon balm (Melissa officinalis, L.) extract on the formation of advanced glycation end products. Food Chemistry 129: 267-271.

24. Wu JW, Hsieh CL, Wang HY, Chen HY (2009) Inhibitory effects of guava (Psidium guajava L.) leaf extracts and its active compounds on the glycation process of protein. Food Chemistry 113: 78-84.

25. Goodarzi M, Moosavi-Movahedi AA, Habibi-Rezaei M (2014) Hemoglobin fructation promotes heme degradation through the generation of endogenous reactive oxygen species. Spectrochimica Acta Part a-Molecular and 
Biomolecular Spectroscopy. 130: 561-567.

26. GhoshMoulick R, Bhattacharya J, Roy S (2007) Compensatory secondary structure alterations in protein glycation. Biochimica Et Biophysica ActaProteins and Proteomics 1774: 233-242.

27. John WG, Lamb EJ (1993) The Maillard or Browning Reaction in Diabetes. Eye 7: 230-237.

28. Barati D, Moeinzadeh S, Karaman O, Jabbari E (2014) Time dependence of material properties of polyethylene glycol hydrogels chain extended with short hydroxy acid segments. Polymer 55: 3894-3904.

29. Es-haghi A, Shariatizi S, Ebrahim-Habibi A, Nemat-Gorgani M (2012) Amyloid fibrillation in native and chemically-modified forms of carbonic anhydrase II: Role of surface hydrophobicity. Biochimica Et Biophysica Acta-Proteins and Proteomics 1824: 468-477.

30. Nilsson MR (2004) Techniques to study amyloid fibril formation in vitro. Methods 34: 151-160.

31. Ortwerth BJ, James H, Simpson G, Linetsky M (1998) The generation of superoxide anions in glycation reactions with sugars, osones, and 3-deoxyosones. Biochemical and Biophysical Research Communications 245: 161-1655.

32. Hunt JV, Bottoms MA, Mitchinson MJ (1993) Oxidative Alterations in the Experimental Glycation Model of Diabetes-Mellitus Are Due to Protein Glucose Adduct Oxidation - Some Fundamental Differences in Proposed Mechanisms of Glucose-Oxidation and Oxidant Production. Biochemical Journal 291: 529535 .

33. Sakai M, Oimori M, Kasuga M (2002) Experimental Studies on the Role of Fructose in the. Kobe J Med Sci 48: 125-136.

34. Wu JW, Hsieh CL, Wang HY, Chen HY (2009) Inhibitory effects of guava (Psidium guajava L.) leaf extracts and its active compounds on the glycation process of protein. Food Chemistry 113: 78-84.

35. Sattarahmady N, Moosavi-Movahedi AA, Ahmad F (2007) Formation of the molten globule-like state during prolonged glycation of human serum albumin, Biochim Biophys Acta 6: 933-942.

36. Panter SS (1994) Release of Iron from Hemoglobin. Hemoglobins Pt B 231: 502-514.
37. Klunk WE, Jacob RF, Mason RP (1999) Quantifying amyloid by Congo red spectral shift assay. Amyloid, Prions, and Other Protein Aggregates. 309: 285305

38. Bose T, Chakraborti AS (2008) Fructose-induced structural and functional modifications of hemoglobin: Implication for oxidative stress in diabetes mellitus. Biochimica Et Biophysica Acta-General Subjects 1780: 800-808.

39. Kang JH (2006) Oxidative modification of human ceruloplasmin by methylglyoxal: An in vitro study. Journal of Biochemistry and Molecular Biology 39: $335-338$

40. Halliwell B, Gutteridge JMC (2007) Free radicals in biology and medicine Oxford University Press, USA.

41. Bouma B, Kroon-Batenburg LMJ, Wu YP (2003) Glycation induces formation of amyloid cross-beta structure in albumin. Journal of Biological Chemistry 278 : 41810-41819.

42. Bakhti M, Habibi-Rezaei M, Moosavi-Movahedi AA Khazaei MR (2007) Consequential alterations in haemoglobin structure upon glycation with fructose: Prevention by acetylsalicylic acid. Journal of Biochemistry 141: 827833.

43. Vigneshwaran N, Bijukumar G, Karmakar N, Anand S, Misra A (2005) Autofluorescence characterization of advanced glycation end products of hemoglobin. Spectrochimica Acta Part a-Molecular and Biomolecular Spectroscopy 61: 163-170.

44. Rosen CG, Weber G (1969) Dimer Formation from 1-Anilino-8Naphthalenesulfonate Catalyzed by Bovine Serum Albumin. A New Fluorescent Molecule with Exceptional Bindind Properties. Biochemistry 8: 3915-3920.

45. Bose T, Bhattacherjee A, Banerjee S, Chakraborti AS (2013) Methylglyoxalinduced modifications of hemoglobin: Structural and functional characteristics. Archives of Biochemistry and Biophysics 529: 99-104.

46. Mahomoodally FM, Subratty AH, Gurib-Fakim A (2012) Antioxidant antiglycation and cytotoxicity evaluation of selected medicinal plants of the Mascarene Islands, Complementary and Alternative Medicine 12: 165.

47. Loske C, Neumann A, Cunningham AM (1998) Cytotoxicity of advance glycation end product is mediated by oxidative stress, Journal of Neural Transmission 105: 1005-1015. 